\title{
Using extracorporeal membrane oxygenation to rescue acute myocardial infarction with cardiopulmonary collapse: the impact of early coronary revascularization
}

\author{
MY Wu \\ From 23rd World Congress of the World Society of Cardio-Thoracic Surgeons \\ Split, Croatia. 12-15 September 2013
}

\section{Background}

To investigate the therapeutic impact of combining extracorporeal membrane oxygenation (ECMO) and early coronary revascularization on acute myocardial infarction (AMI)-induced cardiopulmonary collapse.

\section{Methods}

This retrospective study included 35 consecutive patients rescued by ECMO for AMI -induced cardiopulmonary collapse in a single institution between June 2003 and December 2011. Coronary revascularization was performed soon after ECMO initiation. Percutaneous coronary intervention (PCI) was the primary revascularization strategy. Coronary artery bypass grafting (CABG) was performed if an unsuitable anatomy or unsatisfactory result of PCI. Comparisons were performed in groups with different revascularization strategies and outcomes.

\section{Results}

Among the 35 patients, 16 underwent CABG and 1 was bridged to transplant after CABG. Compared to patients receiving $\mathrm{PCI}$ only, the CABG group showed similar results in ECMO weaning ( $58 \%$ vs. $69 \%, \mathrm{p}=0.51$ ), hospital discharge ( $32 \%$ vs. $50 \%, \mathrm{p}=0.27)$, and left ventricular ejection fraction before discharge ( $45 \%$ vs. $49 \%, \mathrm{p}=0.92$ ). Regardless of revascularization strategies, this protocol achieved an ECMO-weaning rate of $63 \%$ and a hospital discharge rate of $40 \%$. Dialysis-dependent acute renal failure (OR 5.4, 95\% CI 1.1-27.5) and profound anoxic

Correspondence: archer3627@gmail.com

Department of Cardiac Surgery, Chang Gung Memorial Hospital, Taoyuan, Taiwan encephalopathy (OR 5.4, 95\% CI 1.1-27.5) predicted non-weaning of ECMO. Age > 60 years (OR 7.3, 95\% CI $1.1-51.0)$ and profound anoxic encephalopathy (OR 24.6, 95\% CI 2.3-263.0) predicted in-hospital mortality. The major cardiovascular adverse effect (MACE) -free survival was $77 \%$ in the first year after discharge.

\section{Conclusions}

Early revascularization on ECMO is practical to preserve myocardial viability and bridge patients collapsing with AMI to recovery.

Published: 11 September 2013

doi:10.1186/1749-8090-8-S1-082

Cite this article as: Wu: Using extracorporeal membrane oxygenation to rescue acute myocardial infarction with cardiopulmonary collapse: the impact of early coronary revascularization. Journal of Cardiothoracic Surgery 2013 8(Suppl 1):O82.

Submit your next manuscript to BioMed Central and take full advantage of:

- Convenient online submission

- Thorough peer review

- No space constraints or color figure charges

- Immediate publication on acceptance

- Inclusion in PubMed, CAS, Scopus and Google Scholar

- Research which is freely available for redistribution

\section{Biomed Central}

(C) 2013 Wu; licensee BioMed Central Ltd. This is an Open Access article distributed under the terms of the Creative Commons Attribution License (http://creativecommons.org/licenses/by/2.0), which permits unrestricted use, distribution, and reproduction in any medium, provided the original work is properly cited. 